Article

\title{
Using Optical Attenuation Coefficient to Monitor the Efficacy of Fluoride and Nd:YAG Laser to Control Dentine Erosion
}

\author{
Marcia C. Dias-Moraes ${ }^{1}\left(\mathbb{D}\right.$, Cassio A. Lima ${ }^{1}\left(\mathbb{D}\right.$, Anderson Z. Freitas ${ }^{1}$, Ana Cecilia C. Aranha ${ }^{2}$ \\ and Denise M. Zezell ${ }^{1, * \mathbb{D}}$ \\ 1 Instituto de Pesquisas Energeticas e Nucleares, Universidade de Sao Paulo, Sao Paulo 05508-000, Brazil; \\ mcdias2005@gmail.com (M.C.D.-M.); cassiolima@usp.br (C.A.L.); freitas.az@ipen.br (A.Z.F.) \\ 2 Faculdade de Odontologia, Universidade de Sao Paulo, Sao Paulo 05508-000, Brazil; acca@usp.br \\ * Correspondence: zezell@usp.br; Tel.: +55-11-3133-9370
}

Received: 23 December 2018; Accepted: 21 February 2019; Published: 9 April 2019

\begin{abstract}
The present study evaluated the protective effects that are induced by fluoride and Nd:YAG laser irradiation to control dentine erosion. One hundred and twenty bovine dentine slabs were eroded with citric acid twice a day for a total period of 15 days. At day 10, the samples were randomly assigned into eight groups: C (Control); F (Fluoride); L1 (Nd:YAG laser, $1 \mathrm{~W}, 100 \mathrm{~mJ}$, $\left.79.5 \mathrm{~J} \cdot \mathrm{cm}^{-2}\right)$; L2 (Nd:YAG laser, $0.7 \mathrm{~W}, 70 \mathrm{~mJ}, 55.7 \mathrm{~J} \cdot \mathrm{cm}^{-2}$ ); L3 (Nd:YAG laser, $0.5 \mathrm{~W}, 50 \mathrm{~mJ}$, $\left.39.7 \mathrm{~J} \cdot \mathrm{cm}^{-2}\right) ; \mathrm{F}+\mathrm{L} 1 ; \mathrm{F}+\mathrm{L} 2$; and, F + L3. Optical Coherence Tomography images were collected from the surface of the samples in order to monitor the alterations that were induced by erosion and the effectiveness of each treatment using the Optical Attenuation Coefficient (OAC). OAC values that were calculated for samples from groups C, F, L1, L3, FL1, and FL3 indicated no protective effects against the progression of erosive lesions. Samples from L2 and FL2 groups presented OAC values, indicating that laser irradiation under this condition did not induce the formation of craters on dentine tissue and promoted sufficient chemical and morphological changes to avoid the progression of dentine erosion.
\end{abstract}

Keywords: demineralization; dental erosion; optical coherence tomography; Nd:YAG laser; fluoride; optical attenuation coefficient; OCT; dentine erosion

\section{Introduction}

Dental erosion is defined as the irreversible loss of mineralized tissue that is caused by acidic agents not involving bacteria [1]. Tooth wear that is induced by erosion has multifactorial etiological factors whose prevalence has increased in recent years and affects almost one-third of the general population [2], resulting in more cases of dental erosion and cervical dentine hypersensitivity [3]. The progression of dental erosion can lead to complications, such as fractures, tooth decay, aesthetics issues (yellow and stained teeth), and eventually tooth loss. Current treatment modalities are based on multifactorial approaches and may include nutritional education, psychological care, fluoride application, laser irradiation, remineralizing solutions, and even tooth restoration [4,5]. Despite the options that are available to treat dental erosion, some studies have focused on preventive strategies in order to avoid demineralization and caries, such as the development of wireless biosensors that are able to monitor analytical parameters that are involved in the pathogenesis of tooth erosion (e.g., intra-oral $\mathrm{pH}$ ) [2,6].

Localized heating that is induced by high intensity infrared laser irradiation promotes changes in the microstructure of dental tissues, therefore preventing the appearance and progression of dental erosion $[7,8]$. The use of Nd:YAG laser $(1064 \mathrm{~nm})$ for caries prevention as well as for treating 
dentine hypersensitivity has been well demonstrated [9-12]. However, few studies have focused on evaluating the effects of Nd:YAG laser to control the progression of dentine erosion [13-15]. Besides, contradictory results have been reported due to the different laser parameters, erosive protocols, as well as the association of laser irradiation to different therapeutic agents. Thus, the present study evaluated the protective effects of topical fluoride and Nd:YAG laser irradiation as methods to control dentine erosion based on the Optical Attenuation Coefficient (OAC) that was calculated from Optical Coherence Tomography (OCT) images.

OCT is a high-resolution, non-invasive, and non-destructive technique that allows the evaluation of both surface characteristics and the quantitative loss of tooth structures $[1,16]$. The method generates sub-surface images that are based on the magnitude and echo time delay of backscattered light from different depths of tissue-sample $[17,18]$. The potential applications of OCT as a tool to quantitatively and qualitatively monitor the changes in the optical properties of oral tissues has been well demonstrated through many proof-of-concept studies $[16,17,19,20]$. Besides OCT, quantitative light fluorescence (QLF) is also an option in evaluating dental erosion, however it is more expensive. Other techniques that are used to monitor dentine erosion in vivo may include fluorescence, fiber optic transillumination (FOTI), and X-rays, but without longitudinal information [1].

\section{Materials and Methods}

\subsection{Dentine Sample Preparation}

In an in vitro study, 120 bovine dentine slabs were submitted to the erosive demineralization challenge twice a day for a total period of 15 days. The dentine samples were prepared from bovine incisors. Dental crowns were separated from the roots using a double-sided diamond disc in low-speed rotation. The vestibular dentine surfaces were ground flat with water-cooled abrasive discs (120, 400, 600-Buelher, Lake Bluff, IL, USA) and then placed in a metallographic cutter (LabCut—Extec Corp., Enfield, CT, USA) for obtaining the dentine slabs $(4 \times 4 \times 2 \mathrm{~mm}$ ). The samples were individually immersed for $20 \mathrm{~min}$ in a solution of $80 \mathrm{~mL}$ of citric acid (citric acid monohydrate $-\mathrm{C}_{6} \mathrm{H}_{8} \mathrm{O}_{7} . \mathrm{H}_{2} \mathrm{O} ; \mathrm{M}: 210.14 \mathrm{~g} \cdot \mathrm{mol}^{-1} ; \mathrm{pH}: 2.3 ; 0.05 \mathrm{M}$ ) and washed by distilled water for $15 \mathrm{~s}$ at the end of each cycling. After 10 days, visual lesions were observed on dentine specimens. Samples were randomly distributed into eight groups and submitted to treatments, as described in Table 1.

Table 1. Experimental groups.

\begin{tabular}{|c|c|c|c|c|}
\hline Group & Treatment & Power (W) & Energy (mJ) & Energy Density $\left(\mathrm{J} \cdot \mathrm{cm}^{-2}\right)$ \\
\hline$C(n=15)$ & Control & - & - & - \\
\hline$F(n=15)$ & Fluoride & - & - & - \\
\hline $\mathrm{L} 1(\mathrm{n}=15)$ & Laser irradiation & 1 & 100 & 79.5 \\
\hline $\mathrm{L} 2(\mathrm{n}=15)$ & Laser irradiation & 0.7 & 70 & 55.7 \\
\hline L3 $(\mathrm{n}=15)$ & Laser irradiation & 0.5 & 50 & 39.7 \\
\hline FL1 $(n=15)$ & Fluoride + Laser irradiation & 1 & 100 & 79.5 \\
\hline FL2 $(n=15)$ & Fluoride + Laser irradiation & 0.7 & 70 & 55.7 \\
\hline FL3 $(n=15)$ & Fluoride + Laser irradiation & 0.5 & 50 & 39.7 \\
\hline
\end{tabular}

Samples from groups F, FL1, FL2, and FL3 received topical application of sodium fluoride 2\% (GEL Flutop Neutral—SS White, Rio de Janeiro, RJ, Brazil) for four minutes, followed by distilled water baths for $10 \mathrm{~s}$, and then dried with absorbent paper. Samples from FL1, FL2, and FL3 were submitted to laser irradiation after fluoride application.

Dentine specimens of laser-treated groups (L1, L2, L3, FL1, FL2, and FL3) were irradiated using a Nd:YAG laser device (Power Laser TM ST6, Lares Research ${ }^{\circledR}$, Chico, CA, USA) operating at wavelength of $1.064 \mu \mathrm{m}$ and temporal width of $120 \mu \mathrm{s}$. The irradiation parameters of each lased 
group are described in Table 1. The slabs were irradiated in contact mode, scanning the surfaces by hand using a fibre optic system with $400 \mu \mathrm{m}$ of spot size. The energy per pulse was calibrated using an energy/power meter prior each irradiation. After receiving treatment, the samples were re-submitted to erosive cycles for five days.

\subsection{OCT Image Acquisition and Calculation of $O A C$}

The OCT images were collected from the surface of the samples in order to monitor the alterations that are induced by erosion, as well as the protection effectiveness promoted by each treatment modality. Tomographic images were obtained before the erosion cycle (day 0 ), immediately after receiving treatment (day 10), and at the end of demineralization challenge (day 15). The images were collected using an OCT system (OCT-OCP930SR, Thorlabs Inc., Newton, NJ, USA) operating with a super-luminescent light-emitting diode as light source (SLED) with $2 \mathrm{~mW}$ of optical power, central wavelength of $930 \mathrm{~nm}$, spectral bandwidth of $100 \mathrm{~nm}$, axial resolution of $4.0 \mu \mathrm{m}$, and lateral resolution of $6.0 \mu \mathrm{m}$. OAC was calculated from OCT images (B-scan) using an algorithm that was developed by our team on LabView plataform (National Instruments, Austin, TX, USA). For this, the attenuation of the OCT signal penetrating the dentine matrix was estimated by fitting its curve with a Beer-Lambert-type function, in which the intensity of the backscattered light is described as a function of the penetration depth in the sample:

$$
\mathrm{I}(\mathrm{z})=\mathrm{I}_{0} \cdot \mathrm{e}^{-2 \mathrm{az}}+\mathrm{C}
$$

where $\mathrm{I}(\mathrm{z})$ represents the detected intensity as a function of depth $z, \mathrm{I}_{0}$ is the incident intensity, a is the OAC, and $\mathrm{C}$ is a constant.

The method is described in more detail in Cara et al. (2014) [21]. The images were acquired in the same position at all time by a mark made with a dental drill on the sides of the samples, allowing for its assessment over time.

\subsection{Statistical Analysis}

OAC values that were calculated from OCT images of each group were submitted to Shapiro-Wilk normality test. Data were compared using One-way ANOVA, followed by Tukey's test and considered to be statistically different for $\mathrm{p}$-values $<0.05$.

\section{Results}

Representative OCT images that were collected from untreated dentine at day 0, 10, and 15 are shown in Figure $1 \mathrm{~A}-\mathrm{C}$. The emergence and progression of the erosive lesion induced by the demineralization challenge can be easily identified in the tomographic images. Figure 1D shows the numerical fits calculated from the OCT signals that were extracted from regions delimited by red polygons in each image. The magnitude of OCT signal is represented as a function of the optical penetration depth. OAC values that were calculated from each numerical fit are depicted in Figure 1E. As long as demineralization increases, the light is less attenuated and it penetrates deeper into the sample, so that the OCT signal decays more slowly and the optical attenuation coefficient decreases (Figure 1E). 


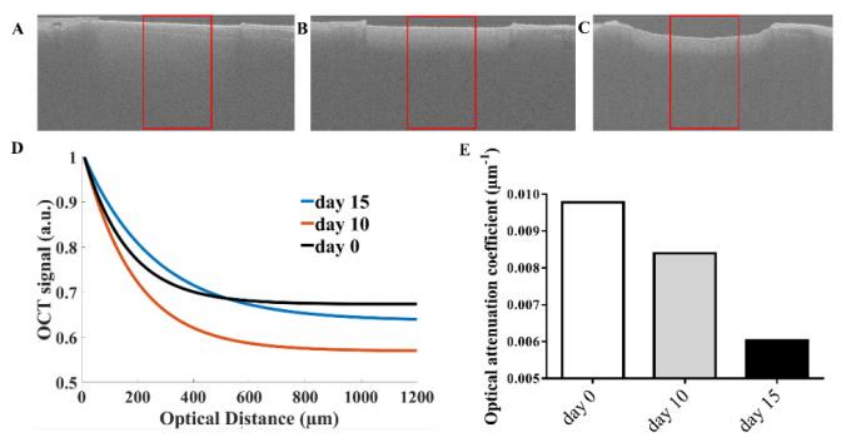

Figure 1. Representative Optical Coherence Tomography (OCT) images collected from untreated dentine at day 0 (A), 10 (B), and 15 (C). Numerical fits calculated from OCT signals extracted from regions delimited by red polygons in each image are shown in D. OAC values calculated from each numerical fit are depicted in $\mathbf{E}$.

Figure 2 shows the averaged values and standard errors of OAC values that were obtained for each group before the erosion cycle (day 0 ), immediately after receiving treatment (day 10), and at the end of demineralization challenge (day 15). OCT signal attenuation is quantity sensitive to dentine demineralization, and therefore it can be used as a marker for detecting demineralization [16]. A decrease in the OAC values after receiving treatment indicates that demineralization is progressing, i.e., the treatment modality was not able to induce chemical and morphological changes to improve the resistance of dentine to acid challenge. On the other hand, no alterations in the OAC values after treatment indicate that demineralization is not progressing, therefore suggesting the protective effects that are induced by treatment [11].
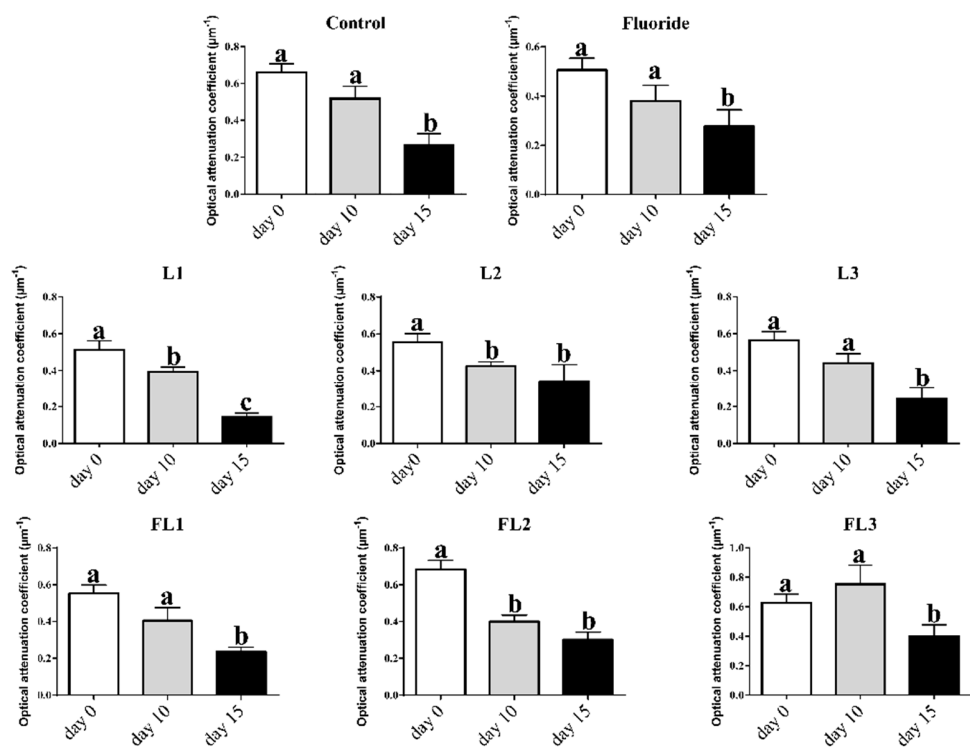

Figure 2. Averaged values of optical attenuation coefficient calculated from OCT images that were collected before the erosion cycle (day 0), immediately after receiving treatment (day 10) and at the end of demineralization challenge (day 15). Bars denote standard error. Distinct letters indicate statistically significant differences $(\mathrm{p}<0.05)$, according to Tukey's test.

A decrease in the OAC values calculated from OCT images that were collected from control, fluoride, L1, L3, FL1, and FL3 groups were evidenced at the end of the experiment (day 15), indicating no protective effects against the progression of erosive lesions in the specimens from these groups. No significant statistical differences were obtained comparing the OAC values at day 10 and 15 from 
samples of L2 and FL2 groups, suggesting that treatment was effective in avoiding the progression of erosion lesions.

\section{Discussion}

The potential applications of Nd:YAG laser irradiation for treating dental hypersensitiviy has been well demonstrated through many investigations over the last years [12]. When considering that dental erosion and dentine hypersensitivity are often related, it would be interesting if the laser could control the progression of dentine erosion as well as to treat dentine hypersensitivity at the same time. However, few studies have focused on evaluating the effects of the Nd:YAG laser to avoid the progression of erosive lesions [13-15]. In light of this, the present study evaluated the effects of Nd:YAG laser irradiation and topical fluoride as methods to control dentine erosion based on the optical attenuation coefficients that were calculated from OCT images. Several laser energy densities, either associated with fluoride application or not, were evaluated.

Fluoride treatment it is a well-established solution for preventing and controlling dental erosion. Its protective effect results from the formation of CaF2 like material on tissue surface, which increases the dentine resistance to acids. Our findings indicate that fluoride alone was not able to avoid the progression of dentine erosion that is induced by acid challenge. However, it is important to notice that the dentine specimens were submitted to a single application of fluoride instead of daily applications, as recommended by medical guidelines [22-25]. Besides, many authors agree that acid drinks can easily remove the CaF2 layer. Thus, the benefits of its implementation alone would be quickly neutralized $[26,27]$.

Increases in demineralization were also observed in the specimens from groups L1, FL1, L3, and FL3, indicating that laser irradiation under these conditions was not able to control dentine erosion, regardless of fluoride application. The positive effects promoted by laser irradiation are dependent on the parameters used, mostly on the energy density. The progression of dentine erosion in samples from groups L3 and FL3 probably occurred due to the low energy that was used to irradiate the samples, which did not induce sufficient chemical and morphological changes to improve the resistance of dentine to acid challenge. On the other hand, high energy density may induce the formation of craters on the dentine surface, which also leads to the progression of dentine erosion [28]. Wan-Hong and coworkers evaluated the formation of craters on dentine specimens that were irradiated by Nd:YAG laser with different energy conditions (50, 100, and $150 \mathrm{~mJ}$ ). According to their results, $50 \mathrm{~mJ}$ does not produce crater formation. On the other hand, craters on dentine surface were evidenced on samples irradiated with 100 and $150 \mathrm{~mJ}$ [28]. Thus, it is possible that the high power employed to irradiate the specimens from L1 and FL1 (79.5 mJ) also induced craters on dentine samples, enabling acid diffusion into the dentine tubules and, consequently, the progression of erosive lesions.

No significant differences were obtained for the OAC values of dentine samples from L2 and FL2 at day 10 and 15, indicating that laser irradiation under this condition did not induce the formation of craters on dentine tissue and promoted sufficient chemical and morphological changes to avoid the progression of dentine erosion.

Author Contributions: Conceptualization, A.C.C.A. and D.M.Z.; methodology, M.C.D.-M.; software, A.Z.F.; formal analysis, C.A.L.; investigation, M.C.D.-M; data curation, C.A.L.; writing-original draft preparation, C.A.L and M.C.D.-M.; writing-review and editing, C.A.L.; supervision, A.Z.F., D.M.Z. and A.C.C.A.; funding acquisition, A.C.C.A. and D.M.Z.

Acknowledgments: This study was supported by grants from Fundação de Amparo à Pesquisa do Estado de São Paulo/ FAPESP (CEPID: 05/51689-2 and Grant: 2013/09311-9), Conselho Nacional de Desenvolvimento Científico e Tecnológico/ CNPq (INCT: 465763/2014-6, Grant: 449440/2014-1, Grant: 30367/2013-1, PQ: 309902/2017-7, PhD Grant: 141629/2015-0), Coordenação de Aperfeiçoamento de Pessoal de Nível Superior / CAPES (PROCAD: 8888.068505/2014-1).

Conflicts of Interest: The authors declare no conflict of interest. 


\section{References}

1. Joshi, M.; Joshi, N.; Kathariya, R.; Angadi, P.; Raikar, S. Techniques to evaluate dental erosion: A Systematic review of literature. J. Clin. Diagn. Res. 2016, 10, ZE01-ZE07. [CrossRef]

2. Farella, M.; Loke, C.; Sander, S.; Songini, A.; Allen, M.; Mei, L.; Cannon, R.D. Simultaneous wireless assessment of intra-oral $\mathrm{pH}$ and temperature. J. Dent. 2016, 51, 49-55. [CrossRef] [PubMed]

3. Lussi, A. Erosive Tooth Wear-A Multifactorial Condition of Growing Concern and Increasing Knowledge. In Dental Erosion: From Diagnosis to Therapy; Lussi, A., Ed.; Karger: Berlin, Germany, 2006; Volume 20.

4. Litonjua, L.A.; Andreana, S.; Bush, P.J.; Tobias, T.S.; Cohen, R.E. Noncarious cervical lesions and abfractions: A re-evaluation. J. Am. Dent. Assoc. 2003, 134, 845-850. [CrossRef]

5. Jaeggi, T.; Lussi, A. Prevalence, incidence and distribution of erosion. In Dental Erosion from Diagnosis to Therapy; Lussi, A., Ed.; Karger: Berlin, Germany, 2006; Volume 20.

6. Choi, J.E.; Loke, C.; Waddell, J.N.; Lyons, K.M.; Kieser, J.A.; Farella, M. Continuous measurement of intra-oral $\mathrm{pH}$ and temperature: Development, validation of an appliance and a pilot study. J. Oral Rehabil. 2015, 42, 563-570. [CrossRef]

7. Featherstone, J.D.; Nelson, D.G. Laser effects on dental hard tissues. Adv. Dent. Res. 1987, 1, 21-26. [CrossRef] [PubMed]

8. Rohanizadeh, R.; LeGeros, R.Z.; Fan, D.; Jean, A.; Daculsi, G. Ultrastructural properties of laser-irradiated and heat-treated dentin. J. Dent. Res. 1999, 78, 1829-1835. [CrossRef] [PubMed]

9. Hossain, M.; Nakamura, Y.; Kimura, Y.; Yamada, Y.; Kawanaka, T.; Matsumoto, K. Effect of pulsed Nd:YAG laser irradiation on acid demineralization of enamel and dentin. J. Clin. Laser Med. Surg. 2001, 19, 105-108. [CrossRef] [PubMed]

10. Ana, P.A.; Bachmann, L.; Zezell, D.M. Lasers effects on enamel for caries prevention. Laser Phys. 2006, 16. [CrossRef]

11. Pereira, D.L.; Freitas, A.Z.; Bachmann, L.; Benetti, C.; Zezell, D.M.; Ana, P.A. Variation on molecular structure, crystallinity, and optical properties of dentin due to $\mathrm{Nd}$ :YAG laser and fluoride aimed at tooth erosion prevention. Int. J. Mol. Sci. 2018, 19. [CrossRef] [PubMed]

12. Sgolastra, F.; Petrucci, A.; Gatto, R.; Monaco, A. Effectiveness of laser in dentinal hypersensitivity treatment: A systematic review. J. Endod. 2011, 37, 297-303. [CrossRef] [PubMed]

13. Naylor, F.; Aranha, A.C.; Cde, E.P.; Arana-Chavez, V.E.; Sobral, M.A. Micromorphological analysis of dentinal structure after irradiation with Nd:YAG laser and immersion in acidic beverages. Photomed. Laser Surg. 2006, 24, 745-752. [CrossRef]

14. Joao-Souza, S.H.; Scaramucci, T.; Hara, A.T.; Aranha, A.C. Effect of Nd:YAG laser irradiation and fluoride application in the progression of dentin erosion in vitro. Lasers Med. Sci. 2015, 30, 2273-2279. [CrossRef]

15. Chiga, S.; Toro, C.V.; Lepri, T.P.; Turssi, C.P.; Colucci, V.; Corona, S.A. Combined effect of fluoride varnish to Er:YAG or Nd:YAG laser on permeability of eroded root dentine. Arch. Oral Biol. 2016, 64, 24-27. [CrossRef]

16. Popescu, D.P.; Sowa, M.G.; Hewko, M.D.; Choo-Smith, L.P. Assessment of early demineralization in teeth using the signal attenuation in optical coherence tomography images. J. Biomed. Opt. 2008, 13, 054053. [CrossRef] [PubMed]

17. Colston, B.; Sathyam, U.; DaSilva, L.; Everett, M.; Stroeve, P.; Otis, L. Dental OCT. Opt. Express. 1998, 3, 230-238. [CrossRef] [PubMed]

18. Fercher, A.F.; Drexler, W.; Hitzenberger, C.K.; Lasser, T. Optical coherence tomography—Principles and applications. Rep. Prog. Phys. 2003, 66, 239. [CrossRef]

19. Freitas, A.Z.; Zezell, D.M.; Vieira, N.D., Jr.; Ribeiro, A.C.; Gomes, A.S.L. Imaging carious human dental tissue with optical coherence tomography. J. Appl. Phys. 2006, 99, 024906. [CrossRef]

20. Manesh, S.K.; Darling, C.L.; Fried, D. Nondestructive assessment of dentin demineralization using polarization-sensitive optical coherence tomography after exposure to fluoride and laser irradiation. J. Biomed. Mater. Res. Part B 2009, 90, 802-812. [CrossRef]

21. Cara, A.C.; Zezell, D.M.; Ana, P.A.; Maldonado, E.P.; Freitas, A.Z. Evaluation of two quantitative analysis methods of optical coherence tomography for detection of enamel demineralization and comparison with microhardness. Lasers Surg. Med. 2014, 46, 666-671. [CrossRef]

22. Armstrong, W.D.; Brekhus, P.J. Possible relationship between the fluorine content of enamel and resistance to dental caries. J. Dent. Res. 1938, 17, 393-399. [CrossRef] 
23. Aoba, T. The effect of fluoride on apatite structure and growth. Crit. Rev. Oral Biol. Med. 1997, 8, 136-153. [CrossRef]

24. Lussi, A. Dental erosion-Novel remineralizing agents in prevention or repair. Adv. Dent. Res. 2009, 21, 13-16. [CrossRef]

25. Featherstone, J.D. Prevention and reversal of dental caries: Role of low level fluoride. Commun. Dent. Oral Epidemiol. 1999, 27, 31-40. [CrossRef]

26. Hsu, C.Y.; Jordan, T.H.; Dederich, D.N.; Wefel, J.S. Laser-matrix-fluoride effects on enamel demineralization. J. Dent. Res. 2001, 80, 1797-1801. [CrossRef]

27. Magalhaes, A.C.; Rios, D.; Machado, M.A.; Da Silva, S.M.; Lizarelli Rde, F.; Bagnato, V.S.; Buzalaf, M.A. Effect of Nd:YAG irradiation and fluoride application on dentine resistance to erosion in vitro. Photomed. Laser Surg. 2008, 26, 559-563. [CrossRef]

28. Wan-Hong, L.; Kau-Wu, C.; Jiiang-Huei, J.; Chun-Pin, L.; Sze-Kwan, L. A comparison of the morphological changes after Nd-YAG and CO2 laser irradiation of dentin surfaces. J. Endod. 2000, 26, 450-453. [CrossRef]

(C) 2019 by the authors. Licensee MDPI, Basel, Switzerland. This article is an open access article distributed under the terms and conditions of the Creative Commons Attribution (CC BY) license (http://creativecommons.org/licenses/by/4.0/). 